\title{
Determination of Suitable Growth Stage for Application of Fungicide against Stripe Rust in Wheat
}

\section{Amir Afzal, Muhammad Ijaz and Sayed Rashad Ali Shah*}

\section{Barani Agriculture Research Institute, Chakwal, Pakistan.}

Abstract | Wheat is the third most important cereal grain in the world. Stripe rust (Puccinia striiformis f. sp. tritici) of wheat is severely detrimental disease. Improvement of crop through incorporation of resistance is practiced enormously. However, a wheat variety that has been recommended for cultivation may not remain resistant for long because of fluctuating nature of pathogen. Therefore, an alternative management strategy to control diseases is application of suitable fungicide at appropriate growth stage. For this, an experiment was conducted to investigate proper growth stage for application of fungicide to control stripe rust in wheat. Sowings at various dates was done to attain various growth stages at once. Two genotypes $16 \mathrm{C} 038$ and cv. Ihsan 2016 were selected for study. Difenoconazole 25\% was treated @ $0.3 \mathrm{ml} / \mathrm{L}$ of water using Knapsack sprayer. Data regarding yield and yield parameters were recorded and analyzed. Significant difference was observed between treated and untreated plots at various growth stages when treated in susceptible genotype (Ihsan, 2016) and contrary in case of resistant genotype (16C038). As a result, 16C038 showed resistant response whereas Ihsan2016 highly susceptible response. It was revealed that application of fungicide is rational in situation when cultivated crop is prone to disease and is uneconomical otherwise. However, fungicidal spray at heading stage did not boost yield significantly and ineffective from economic point of view.

Received | December 19, 2019; Accepted | August 21, 2020; Published | October 05, 2020

*Correspondence | Sayed Rashad Ali Shah, Barani Agricultural Research Institute, 13km-Talagang Road, Chakwal; Email: rashidali572@ yahoo.com

Citation | Afzal, A., M. Ijaz, S.R.A. Shah. 2020. Determination of suitable growth stage for application of fungicide against stripe rust in wheat. Pakistan Journal of Agricultural Research, 33(4): 714-719.

DOI | http://dx.doi.org/10.17582/journal.pjar/2020/33.4.714.719

Keywords | Puccinia striiformis f. sp., tritici, Triticum aestivum L., Fungicide, Disease management, Yield parameters

\section{Introduction}

W heat (Triticum aestivum L.) is the basic staple food for a large part of population and first domesticated food crops (Khanfri et al., 2018; Waqar et al., 2018). Wheat, rice and maize accomplish 50\% of the calories requirement of the globe (Mateen et al., 2015). Many biotic and abiotic factors affect yield components of wheat responsible for the gap between potential and actual yield. Plant diseases that are emerging more frequently and spreading very rapidly across the globe are making worse pressures on food security.
Rust diseases are the most important limitation to sustainable wheat cultivation wherever crop is cultivated (Wellings, 2011; Afzal et al., 2015). Three rusts can cause heavy losses when epidemics occur, but stripe rust is the most harmful, causing losses ranging from $10-70 \%$ (Chen, 2005). Presently disease is spreading rapidly in region, and has become the largest biotic limitation to wheat production (Singh et al., 2004; Pardey et al., 2013; Schwessinger, 2017). In the country, $70 \%$ area under wheat cultivation is prone to stripe rust (Yahyaoui and Rajaram, 2012) and has caused 13 epidemics since 1947 (Welling, 2011). These epidemics caused national wheat production 
severely damaged (Bux et al., 2012).

Stripe rust was mainly considered a disease of cooler environment $\left(2^{\circ} \mathrm{C}-15^{\circ} \mathrm{C}\right)$, upper altitudes and northern latitudes formerly, but novel strains have better adaptation to warmer climate and countries nearer to the equator. Crop damages can reach 50$100 \%$, due to infected plants and shrivelled grain (Waqar et al., 2018).

Diverse control options are offered for management of stripe rust (Sohl et al., 2012). Development of resistant wheat cultivars to this disease is being focused seriously for improvement in wheat breeding and new technologies are being adopted (Ellis et al., 2014). It is however incontrovertible reality that scientific community has not succeeded in creating the rustfree wheat cultivation situation that was imagined from this breeding investment continuous for more than a century. This is because of the potential of the pathogen to modify genetically to parasitize most of the resistant varieties released. While the prospects have not been achieved.

Rust management through application of fungicides is practice of routine in many countries (Chen 2005; Gomes et al., 2018). In Pakistan application of rusticides is unusual because crop covers huge area and spraying of fungicides might pollute the environment. However, in the situation if cultivars grown on wide region become susceptible despite the fact that these genotypes were resistant during last year. It is not rare but has been observed repeatedly. This is logical scientifically that race pattern of pathogen changes in the struggle of survival. It is consequence when completely resistant (vertical resistant) varieties are recommended for general cultivation. Such genotypes generally lose resistance rapidly. In this situation application of fungicide remains the only option to reduce loss in produce.

Unfortunately, wheat crop faced similar situation in wheat in Northern Punjab and KPK during the cropping season 2018-19. It was observed during surveillance by authors in the districts Attock, Rawalpindi, Chakwal, Mianwali, Jhelum and Gujrat; disease hit the crop severely due to heavy precipitation during March. Disease flourished quickly in conducive environment. The alarming situation was that wheat growers treated fungicides without compulsory information. It was felt sufficient research work has not already been carried on this aspect.

Fungicides will play pivotal role in the management of stripe rust in the foreseeable future in Pakistan since a wide area under wheat cultivation is covered by susceptible cultivars and seed of varieties which showed resistance during the cropping season 2018-19 is not enough to substitute susceptible cultivars. It is need of hour to conduct experiments to generate useful data crucial to suggest fungicide application urgently when cultivars grown are no more resistant and grower may suffer severe loss if environmental conditions become favourable for disease development. The trial has been carried with an objective to determine most appropriate growth stage of host to spray fungicide to achieve potential efficacy and benefits for managing stripe rust disease in wheat.

\section{Materials and Methods}

Research work was executed at the experimental area of Barani Agricultural Research Institute, Chakwal located at latitude 32.93 and longitude 72.85 , in the northern hemisphere to explore appropriate timing of application of fungicide during 2018-19. Genotype Ihsan, 2016 (the prevalent variety adopted by the farming community of rainfed zone of Pakistan) and 16C038 (Advanced line evolved in BARI, Chakwal) were chosen for investigation.Ihsan, 2016 was resistant against stripe rust during previous year but was found prone in the area visited during the surveillance conducted during 2018-19 where as 16C038 showed resistance even under severe epidemic situation. This condition provided the additional opportunity to study the effect of fungicide against the genotypes which behaved differentially against the disease.

Trial was laid out in split plot design with varieties in main plots and growth stages of crop in subplots. Trial was planted in three replications with plot dimensions $9 \mathrm{~m}^{2}$. To achieve crop at various growth stages viz. prebooting, booting, and heading, trial was sown in four dates with an interval of twenty days. Difenoconazole @ $0.3 \mathrm{ml} / \mathrm{L}$ was treated at different growth stages to maintain disease free wheat plants. The disease was allowed to progress in the untreated plots which served as check. This enabled evaluation of impact of application of fungicide at various growth stages. Disease flourished rapidly in the untreated plots. Standard agronomic practices for wheat production 
include selection of land and its preparation, better cultivars, proper fertilizer dose, weeds eradication, true to type seed, proper cultivation, and proper harvesting were followed. Morocco (universal susceptible to wheat rusts) was established round the field trial. Severe disease appeared under nature due to conducive environmental condition for disease development. That is why, no artificial inoculation was carried.

Trial was observed keenly throughout the season. Initial symptoms were observed in first week of March. Data of following yield parameters were recorded at harvesting to quantify the effect of disease on yield.

1. Total Number of grains Spike $^{-1}$

2. Grain weight Spike $^{-1}$

3. 1000 grain weight

4. Yield $\mathrm{kg} \mathrm{ha}{ }^{-1}$

Data recorded was processed systematically and statistical analysis was carried using MSTAT-C. Analysis of variance was computed to determine the level of significant difference among treatments (Steel and Torrie, 1988). Duncan's Multiple Range Test $(\mathrm{P}=0.05)$ (Gomez and Gomez, 1984) was used to compare the means.

\section{Results and Discussion}

The response of genotypes varied in different yield contributing characters studied when fungicide was applied at various growth stages. Data on different parameters of yield potential are presented.

\section{Number of grains spike}

Among the various treatments, maximum mean number of grains spike ${ }^{-1}$ (40.39) was produced by 16C038 (untreated-booting stage) when sown in first week of November, followed by Ihsan, 2016 (39.62) (treated- pre-booting stage) sown in the end of the November (Figure 1). Number of grains were least affected with date of sowing in Ihsan, 2016. 16C038 demonstrated contrary attitude in which date of sowing affected number of grains. However overall yield enhanced in the treatment treated at pre-booting stage and this is prominent in case of susceptible variety.

\section{Grain weight spike $e^{-1}$}

In this study, grain weight spike ${ }^{-1}$ showed significant differences among treatments. A greater range was found in grain weight spike ${ }^{-1}$. The maximum value of (1.48g) for 16C038 (Treated-booting stage) sown in Mid-November, while the minimum for Ihsan, 2016 (Untreated-pre-booting stage) $(0.91 \mathrm{~g})$ sown in late November. Treated with fungicide boosted grain weight in each plot. In pre-booting stage improvement of grain weight in Ihsan, 2016 (Treated-pre-booting stage) (1.33g) sown in late November was maximum. The Grain weight spike ${ }^{-1}$ was recorded for $16 \mathrm{C} 038$ (pre-booting stage) sown in late November, (1.33g) and $(1.24 \mathrm{~g})$ treated and untreated plots respectively (Figure 2).

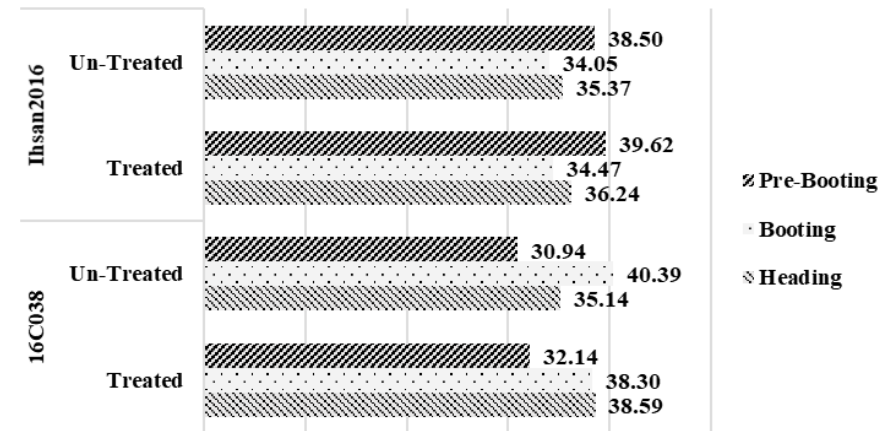

Figure 1: Effect of difenoconazole treated at various growth stages on number of grains spike $e^{-1}$ against stripe rust in wheat.

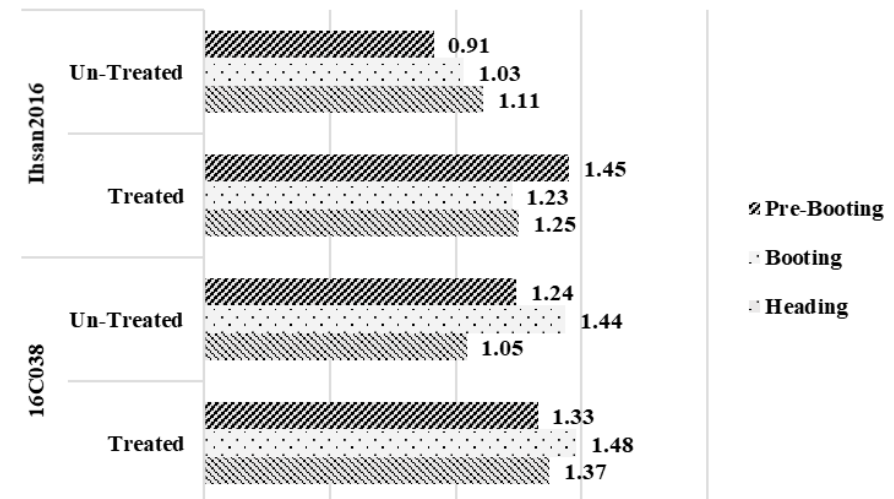

Figure 2: Effect of difenoconazole treated at various growth stages on grains weight spike $e^{-1}$ against stripe rust in wheat.

\section{0-grain weight}

The overall 1000-grain weight ranged from (31.74g) $16 \mathrm{C} 038$ (Untreated-pre-booting stage) sown in late November to (43.04g) Ihsan, 2016 (Treated-prebooting stage) sown in late November (Figure 3). Ihsan, 2016 is susceptible but grains were heavier even when sown late as compared to $16 \mathrm{C} 038$ which exhibited resistance against disease but performance of genotype affected severely when sown late. Plots sown earlier (Heading and Booting stage) were tended to be having lower grain weight even if treated.

\section{Yield $k g h a^{-1}$}

Yield is a complicated parameter affected by various 
factors contributing towards enhanced yield. Sowing time, disease severity. The maximum grain yield was recorded for Ihsan, 2016 (4481 $\left.\mathrm{kgha}^{-1}\right)$ followed by 16C038 (4177 $\left.\mathrm{kgha}^{-1}\right)$ under condition treated at pre-booting stage with difenoconazole in late sowing. Application of fungicide (difenoconazole) did not boost yield considerably when treated at booting or heading stage (Figure 4).

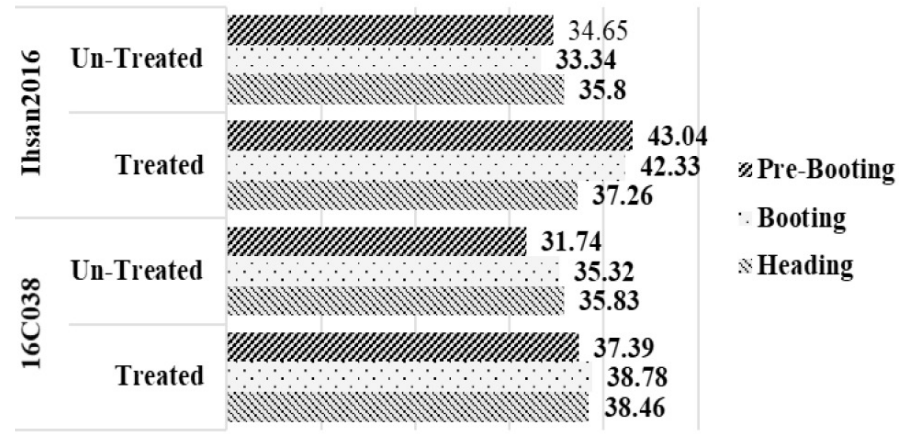

Figure 3: Effect of difenoconazole treated at various growth stages on 1000 grain weight (gm) against stripe rust in wheat.

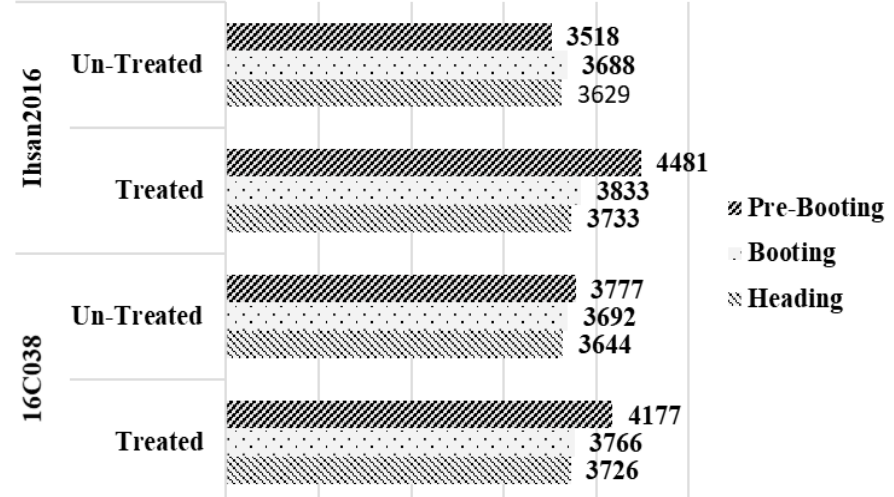

Figure 4: Effect of difenoconazole treated at various growth stages on yield $\left(\mathrm{kgha}^{-1}\right)$ against stripe rust in wheat.

Rusts in wheat, have been one of the major threats to wheat farming since time immemorial data, wherever crop is cultivated. Under the said scenario, wheat breeding for rust resistance is rationale strategy and only those genotypes are approved for general cultivar those express resistant behaviour. Multilocational screening trials against rusts is crucial component of wheat breeding for yield improvement Emergence of more virulent strains against resistant cultivars is characteristic of obligate pathogens. Resistance genes, become futile because of the attainment of virulence to that specific resistance gene rendering the variety susceptible. Evolution of new plant pathogenic races which may lead to serious epidemics. These epidemics leads increased cost of food and pose a tangible threat to rural livelihoods and food security.
Wheat stipe rust has become an emerging problem due to rapid development of new races or variants adopted in warmer climate. Epidemics of stripe rust are more frequent around the world and often led to serious yield loss. Narrow genetic background of host cultivated in vast region provides an ideal situation for development of epidemic leading to huge loss and scarcity. It is acting as a fluctuating foe. Area under wheat cultivation is growing continuously rapidly. Alternate strategy is practiced widely Stripe rust. Fungicidal application analysis indicated that fungicidal spray affects all the parameters contributing in yield. However, progression in grain weight was observed more prominently as compared to number of grains when treated with fungicide (Figures 2 and 4). Fungicide spray at pre-booting and booting stage was effective giving maximum harvest whereas treated after heading did not demonstrate useful in terms of yield. Yield improvement in the plots treated at pre-booting stage was considerable i.e. application of fungicide at heading stage is not advantageous economically. This finding is analogous to work conducted in other parts of world (Yang et al., 1991; Viljanen et al., 2002; Bradley, 2004).

Delayed sowing of wheat decreases span of the crop vegetative and reproductive stages and causes reduced yield (Akmal et al., 2011; Kalwar et al., 2018). Moreover, various genotypes respond differentially to sowing time (Marasini et al., 2016). Sowing trial at various dates enabled to achieve various growth stages at once and enabled to detect the appropriate stage of application of fungicide. However, hid precise yield potential of varieties affecting various parameters. Effect of fungicide was most pronounced at pre-booting stage. It was noted 16C038 (resistant genotype) did not improve yield when treated whereas, response of Ihsan, 2016 (susceptible genotype) was more effective and yield boosted significantly at prebooting stage.

\section{Conclusions and Recommendations}

Extensive research has been carried out to develop resistant varieties for stripe rust control in this region. However, it is usual that only few cultivars are cultivated at a time occupying status of mega cultivar. Foremost reason of this situation is preference of farmer. This provides ideal situation for developing virulent strains leading to appearance of disease in epidemic form. In this situation there is 
no alternative strategy but application of fungicide. Precise information is compulsory to manage an unexpected epidemic of stripe rust. Awareness in farmer is key of success to fight against food security at global level. Study conducted revealed application of fungicide is cost effective if treated in susceptible variety at the stage when disease initiates and it will be wastage of resources in case of resistant variety. Fungicidal spray at later stage is no more economical. The effort generated practical information regarding application of fungicides specifically labelled for the management of stripe rust of wheat in Pakistan has removed hinderance in the instantaneous declaration of recommendations for fungicide application to manage the disease. The information will greatly help to comprehend the procedure and to invent control measures to alleviate the damages caused by the disease in Pakistan.

\section{Novelty Statement}

The stripe rust of wheat remains a pathological issue and a threat to wheat production worldwide. Our investigations suggest that future stripe rust epidemics are likely to occur due to viz, presence and emergence of aggressive strains, limited availability of resistant wheat cultivar, and frequent conducive weather events. Keeping in view of that, we believe that fungicide may play a pivotal role in stripe rust management, so experiment was conducted to explore optimal fungicide application timing/ crop growth stages. This kind of research work not reported so far in Pakistan.

\section{Author's Contribution}

M.I. conceived of the presented idea and added technical input at every step. A.A. carried out the experiment, collected data, developed the theory and performed the computations for analysis. S.R.A.S. wrote the manuscript and overall management of manuscript. M.I. and S.R.A.S. verified the analytical methods. M.I. supervised the findings of this work. All authors discussed the results and contributed to the final manuscript.

\section{Conflict of interest}

The authors have declared no conflict of interest.

\section{References}

Ali, M.A., M. Ali and Q.M. Din. 2004. Determi- nation of grain yield of different wheat varieties as influenced by planting dates in agro-ecological conditions of Vehari. Pak. J. Life Soc. Sci., 2(1): 5-8.

Afzal, A., A. Riaz, J.I. Mirza and K.N. Shah.2015. Status of wheat breeding at global level for combating Ug99-A Review. Pak. J. Phytopathol., 27(2): 211-218.

Akmal,M., S.M. Shah, M. Asim and M. Arif. 2011. Causes of yield reduction by delayed planting of hexaploid wheat in Pakistan. Pak. J. Bot., 43(5): 2561-2568.

Bradley, R.S., 2004. UK rules for growing Wheat: Might Australian crops comply. http://www. grdc.com.au/growers/res_upd/s04/Sylvester. htm (2007/02/22).

Bux, H., A. Rasheed, M.A. Siyal, A.G. Kazi, A.A. Napar and A.M. Kazi. 2012. An overview of stripe rust of wheat (Puccinia striiformis f. sp. tritici) in Pakistan. Arch. Phytopathol. Plant Prot., 45(19): 2278-2289. https://doi.org/10.1 080/03235408.2012.726399

Chen, X.M., 2005. Epidemiology and control of stripe rust [Puccinia striiformis f. sp. tritici] on wheat. Can. J. Plant Pathol., 27(3): 314-337. https://doi.org/10.1080/07060660509507230

Chen, Y.L., S.X. Xie, Y.H. Sun and H.K. Qin. 1984. Preliminary research on the control of stripe rust (Puccinia striiformis) of wheat by triadimefon. China J. Plant Prot., 11: 241-246.

Ellis, J.G., E.S. Lagudah, W. Spielmeyer and P.N. Dodds. 2014. The past, present and future of breeding rust resistant wheat. Front. Plant Sci., 5: 641. https://doi.org/10.3389/ fpls.2014.00641

Gomez, K.A. and A.A. Gomez. 1984. Statistical Procedures for Agricultural Research. New York: John Wiley.

Gomes, C., A.S. Almeida, J. Coutinho, R. Costa, N. Pinheiro, J. Coco, A. Costa, A.S. Bagulho and B. Maçãs. 2018. Foliar fungicide application as management strategie to minimize the growing threat of yellow rust on wheat in Portugal. Emir. J. Food Agric., pp. 715-724. https://doi.org/10.9755/ejfa.2018.v30.i9.1793

Kalwar, Z.A., A. Tunio. M.Y. Shaikh, I.K. Jatoi and Q. Jogi. 2018. Impact of sowing dates on the growth and yield of wheat variety benazir-2013, Sindh Province, Pakistan. Int. J. Agron. Agric. Res., 12(5): 65-71.

Khanfri, S., M. Boulif and R. Lahlali. 2018. Yellow 
Rust (Puccinia striiformis): A serious threat to wheat production worldwide. Not. Sci. Biol.,10(3):410-423.https://doi.org/10.15835/ nsb10310287

Marasini, D., S. Marahatta, S.M. Dhungana and R. Acharya. 2016. Effect of Date of Sowing on Yield and Yield Attributes of Different Wheat Varieties under Conventional Tillage in SubHumid Condition of Chitwan District of Nepal. Inter. J. Appl. Sci. Biotech., 4. 27. 10.3126/ ijasbt.v4i1.14335. https://doi.org/10.3126/ ijasbt.v4i1.14335

Mateen, A., M.A. Khan, A. Rashid, M. Hussain, S.U. Rehman and M. Ahmed. 2015. Identification of leaf rust virulence pattern on wheat germplasm in relation to environmental conditions in Faisalabad. Acad. J. Agric. Res., 3: 137-155.

Pardey, P.G., J.M. Beddow, D.J. Kriticos, T.M. Hurley, R.F. Park, E. Duveiller, R.W. Sutherst, J.J. Burdon and D. Hodson. 2013. Right-sizing stem-rust research. Science, 340: 147-148. https://doi.org/10.1126/science.122970

Schwessinger, B., 2017. Fundamental wheat stripe rust research in the $21^{\text {st }}$ century. New Phytol., 213(4): 1625-1631. https://doi. org/10.1111/nph.14159

Singh R.P.,H.M.William,J.Huerta-Espino and G. Rosewarne. 2004. Wheat rust in Asia: Meeting the challenges with old and new technologies. In: New directions for a diverse planet. Proc. $4^{\text {th }}$ Int. Crop Sci. Cong. Brisbane, Australia.
Solh, M., K. Nazari, W. Tadesse and C.R. Wellings. 2012. The growing threat of stripe rust worldwide. In Borlaug Global Rust Initiative (BGRI) conference, Beijing, China. pp. 1-4.

Steel, R.G. and J.H. Torrie. 1980. Principles and procedures of statistics. $2^{\text {nd }}$ Edition. New York, NY; Mc-Graw Hills.

Viljanen, S., R. Parkes, T. Armour and M. Cromey. 2002. Fungicide control of stripe rust in wheat: Protection or eradication? N. Z. Plant Prot., 55: 336-340. https://doi.org/10.30843/ nzpp.2002.55.3902

Waqar, A., S.H. Khattak, S. Begum, T. Rehman, Rabia, A. Shehzad, W.Ajmal, S.S. Zia, I. Siddiqi and G.M. Ali. 2018. Stripe rust: A review of the disease, Yr genes and its molecular markers. Sarhad J. Agric., 34(1): 188-201. https://doi. org/10.17582/journal.sja/2018/34.1.188.201

Wellings, C.R., 2011. Global status of stripe rust: A review of historical and current threats. Euphytica, 179: 129-141. https://doi. org/10.1007/s10681-011-0360-y

Yahyaoui, A. and S. Rajaram. 2012. Meeting the challenge of yellow rust in cereal crops. Proc. $2^{\text {nd }}, 3^{\text {rd }}, 4^{\text {th }}$ Reg. Conf. Yellow Rust Central West Asia North Africa (CWANA) Region. ICARDA.

Yang, Z.W., Z.Q. Li, M.L. Jia and X.Q. Sun. 1991. The initial study of economic injury level (EIL) of stripe rust of winter wheat. Acta Univ. Agric. Boreali-Occidentalia, 19(Suppl.): 33-38. 